\title{
Impact of Myenteric Plexus Alterations on Diabetes Related Gastrointestinal Dysmotility
}

\author{
Kyung Sik Park \\ Department of Internal Medicine, Keimyung University School of Medicine, Daegu, Korea
}

Article: Gastrointestinal motility changes and myenteric plexus alterations in spontaneously diabetic biobreeding rats Demedts I, Masaoka T, Kindt $S$, et al

(J Neurogastroenterol Motil 2013;19:161-170)

Diabetes mellitus (DM) is a group of chronic metabolic disorder that develops when pancreatic insulin production or utilization is imbalanced. In particular, long-term complications of DM such as renal, cardiovascular, neurologic, ophthalmic and gastrointestinal (GI) diseases constitute the major causes of death or impaired quality of life (QOL). ${ }^{1,2}$ Among these, GI complications are so frequent that more than $75 \%$ of diabetic patients show one or more gastrointestinal symptoms such as early satiety, nausea, vomiting, constipation, diarrhea, abdominal pain and fecal incontinence. ${ }^{3-7}$ It has been widely reported that these GI symptoms result from abnormal GI motility which occurs in the development of diabetes. $^{4-6,8}$

Although autonomic neuropathy involving a diffuse GI tract has been thought as the main mechanism of GI dysmotility due to diabetes, ${ }^{9-11}$ several factors such as abnormal glycemia, morphological changes of the GI tract, and psychiatric disease have been suggested as other causes of GI dysmotility in diabetic patients. ${ }^{12-17}$ In addition, various recent reports have emphasized the importance of enteric apparatuses such as interstitial cells of Cajal (ICCs) or enteric nerves and their transporting systems in the reg- ulation of GI motility. ${ }^{18-21}$ It is well known that impairment of these systems ultimately result in GI dysmotility and associated GI symptoms in various diabetic animal models and patients. ${ }^{22-24}$

Several animal models have been developed to present the characteristics of type 1 (autoimmune destruction of pancreatic beta cells) and type 2 (insulin resistance and failure of compensation by beta cells) diabetes. ${ }^{25}$ Among these models, spontaneously diabetic biobreeding (BB) rats, are considered as an useful model for studying human type1 diabetes because they show destruction of insulin producing pancreatic the beta cells around 2-3 months of age. $^{26}$

In this issue of the journal, the authors investigated the presence of gastric and jejunal dysmotility in spontaneously diabetic $\mathrm{BB}$ rats, ${ }^{27}$ and whether it correlates with autonomic neuropathy or with changes of myenteric innervation. The same group which included the authors of this issue has previously reported that decreased nitrergic motor control and neuronal nitric oxide synthase protein expression in the jejunum may be the primary dysfunction in spontaneously diabetic BB rats with supporting results from in vitro experiments. ${ }^{28}$ In this issue, the authors supple-

Received: December 26, 2012 Revised: February 6, 2013 Accepted: February 6, 2013

(c) This is an Open Access article distributed under the terms of the Creative Commons Attribution Non-Commercial License (http://creativecommons. org/licenses/by-nc/3.0) which permits unrestricted non-commercial use, distribution, and reproduction in any medium, provided the original work is properly cited.

*Correspondence: Kyung Sik Park, MD

Department of Internal Medicine, Dongsan Medical Center, 194 Dongsan-dong, Jung-gu, Daegu 700-712, Korea

Financial support: None.

Tel: +82-53-250-7088, Fax: +82-53-250-7088, E-mail: seenae99@dsmc.or.kr

Conflicts of interest: None. 
mented the results from in vivo experiments including relative risk-interval variability on electrocardiography, gastric emptying time and small intestinal electromyography. With the results of small intestinal electromyography, the research group confirmed that altered inhibitory motor control in the small bowel can be attributed to the loss of nitrergic motor function in spontaneously diabetic BB rats, in a similar manner to the 2,4,6-trinitrobenzenesulfonic acid (TNBS)-induced post-inflammatory small intestinal dysmotility rat model. ${ }^{29}$ Using the relative risk-interval variation study on electrocardiography, the authors concluded that vagal neuropathy is not associated with altered nitrergic motor function. Furthermore, there was no difference in gastric emptying rate between diabetic and control groups. These findings are not consistent with previous studies which showed an association between vagal neuropathy and delayed gastric emptying with altered motor function in a diabetic model..$^{30,31}$ In addition to the authors' conclusion, "short-term follow-up period" should be considered as a possible confounding factor that may lead to incorrect conclusions. The authors also found transient inflammatory infiltration of the jejunal wall in the 8 week-old diabetic group, which was found to disappear in the 16 week-old diabetic group. This finding is consistent with previous reports on the small intestine and colon of $\mathrm{BB}$ rats and a TNBS-induced model. $^{29}$

In summary, the authors conclude that transient small intestinal inflammation followed by loss of myenteric nitric oxide synthase expression and continuing alterations of small intestinal motor function are ultimately associated with GI dysmotility and that this dysmotility is not dependent on hyperglycemia or vagal neuropathy.

There are 2 points which should be considered in future studies. First, it should be examined whether the duration of 16 weeks is long enough to develop long-term GI complications in spontaneously diabetic BB rats since such complications usually take more than several years to develop in human DM patients. Checking several indicators (for example, microalbuminuria or advanced glycation end-product level) which suggest the presence of long-term diabetic complications may be helpful since GI complications are frequently represented with other diabetic complications such as nephropathy or ophthalmopathy.

Second, investigation about ICCs and their communicating systems is recommended considering their important roles in the regulation of GI motility.

\section{References}

1. Talley NJ, Young L, Bytzer P, et al. Impact of chronic gastrointestinal symptoms in diabetes mellitus on health-related quality of life. Am J Gastroenterol 2001;96:71-76.

2. Mokdad AH, Ford ES, Bowman BA, et al. Diabetes trends in the U.S.: 1990-1998. Diabetes Care 2000;23:1278-1283.

3. Bytzer P, Talley NJ, Leemon M, Young LJ, Jones MP, Horowitz M. Prevalence of gastrointestinal symptoms associated with diabetes mellitus: a population-based survey of 15,000 adults. Arch Intern Med 2001;161:1989-1996.

4. Koch KL. Diabetic gastropathy: gastric neuromuscular dysfunction in diabetes mellitus: a review of symptoms, pathophysiology, and treatment. Dig Dis Sci 1999;44:1061-1075.

5. Horowitz M, Fraser R. Disordered gastric motor function in diabetes mellitus. Diabetologia 1994;37:543-551.

6. Enck P, Rathmann W, Spiekermann M, et al. Prevalence of gastrointestinal symptoms in diabetic patients and non-diabetic subjects. Z Gastroenterol 1994;32:637-641.

7. Feldman M, Schiller LR. Disorders of gastrointestinal motility associated with diabetes mellitus. Ann Intern Med 1983;98:378-384.

8. Rothstein RD. Gastrointestinal motility disorders in diabetes mellitus. Am J Gastroenterol 1990;85:782-785.

9. Bian RW, Lou QL, Gu LB, et al. Delayed gastric emptying is related to cardiovascular autonomic neuropathy in Chinese patients with type 2 diabetes. Acta Gastroenterol Belg 2011;74:28-33.

10. Selim MM, Wendelschafer-Crabb G, Redmon JB, et al. Gastric mucosal nerve density: a biomarker for diabetic autonomic neuropathy? Neurology 2010;75:973-981.

11. Keshavarzian A, Iber FL, Vaeth J. Gastric emptying in patients with insulin-requiring diabetes mellitus. Am J Gastroenterol 1987;82:2935.

12. Quan C, Talley NJ, Jones MP, Spies J, Horowitz M. Gain and loss of gastrointestinal symptoms in diabetes mellitus: associations with psychiatric disease, glycemic control, and autonomic neuropathy over 2 years of follow-up. Am J Gastroenterol 2008;103:2023-2030.

13. Abrahamsson H. Gastrointestinal motility disorders in patients with diabetes mellitus. J Intern Med 1995;237:403-409.

14. de Boer SY, Masclee AA, Lamers CB. Effect of hyperglycemia on gastrointestinal and gallbladder motility. Scand J Gastroenterol 1992;27(suppl 194):13-18.

15. Mayhew TM, Carson FL, Sharma AK. Small intestinal morphology in experimental diabetic rats: a stereological study on the effects of an aldose reductase inhibitor (ponalrestat) given with or without conventional insulin therapy. Diabetologia 1989;32:649-654.

16. Clouse RE, Lustman PJ. Gastrointestinal symptoms in diabetic patients: lack of association with neuropathy. Am J Gastroenterol 1989;84:868-872.

17. Tahara T, Yamamoto T. Morphological changes of the villous microvascular architecture and intestinal growth in rats with streptozotocin-induced diabetes. Virchows Arch A Pathol Anat Histopathol 1988;413:151-158.

18. Sanders KM, Koh SD, Ward SM. Interstitial cells of cajal as pacemakers in the gastrointestinal tract. Annu Rev Physiol 2006;68: 
307-343.

19. Mizuta $\mathrm{Y}$, Takahashi T, Owyang C. Nitrergic regulation of colonic transit in rats. Am J Physiol 1999;277(2 Pt1):G275-G279.

20. Huizinga JD. Gastrointestinal peristalsis: joint action of enteric nerves, smooth muscle, and interstitial cells of Cajal. Microsc Res Tech 1999;47:239-247

21. Eglen RM, Peelle B, Pulido-Rios MT, Leung E. Functional interactions between muscarinic $\mathrm{M} 2$ receptors and 5-hydroxytryptamine (5-HT) 4 receptors and beta 3-adrenoceptors in isolated oesophageal muscularis mucosae of the rat. Br J Pharmacol 1996;119:595-601.

22. Kim SJ, Park JH, Song DK, et al. Alterations of colonic contractility in long-term diabetic rat model. J Neurogastroenterol Motil 2011; 17:372-380.

23. Ordög T. Interstitial cells of Cajal in diabetic gastroenteropathy. Neurogastroenterol Motil 2008;20:8-18.

24. He CL, Soffer EE, Ferris CD, Walsh RM, Szurszewski JH, Farrugia G. Loss of interstitial cells of cajal and inhibitory innervation in insulin-dependent diabetes. Gastroenterology 2001;121:427434.
25. King AJ. The use of animal models in diabetes research. $\mathrm{Br} \mathrm{J}$ Pharmacol 2012;166:877-894.

26. Crisá L, Mordes JP, Rossini AA. Autoimmune diabetes mellitus in the BB rat. Diabetes Metab Rev 1992;8:4-37.

27. Demedts I, Masaoka T, Kindt S, et al. Gastrointestinal motility changes and myenteric plexus alterations in spontaneously diabetic biobreeding rats. J Neurogastroenterol Motil 2013;19:161-170.

28. Zandecki M, Vanden Berghe P, Depoortere I, et al. Characterization of myenteric neuropathy in the jejunum of spontaneously diabetic BB-rats. Neurogastroenterol Motil 2008;20:818-828.

29. Demedts I, Geboes K, Kindt S, et al. Neural mechanisms of early postinflammatory dysmotility in rat small intestine. Neurogastroenterol Motil 2006;18:1102-1111.

30. Sanyal SN, Arita M, Ono K. Inhomogeneous derangement of cardiac autonomic nerve control in diabetic rats. Circ J 2002;66:283288.

31. Chang FY, Lee SD, Yeh GH, Wang PS. Influence of blood glucose levels on rat liquid gastric emptying. Dig Dis Sci 1996;41:528-532. 